\title{
Experiência de Prova Prática na Seleção para a Residência Médica: Exeqüibilidade, Segurança e Importância deste Processo de Avaliação
}

\author{
Hands-on Model in the Selection for \\ Medical Residency: Feasibility, Security and \\ Importance of this Evaluation Process
}

PALAVRAS-CHAVE:

- Internato e Residência:

- Avaliação Educacional;

- Educação de Pós-Graduação em Medicina.

\section{KEY WORDS:}

- Internship and Residency;

- Educational Measurement;

- Education, Medical, Graduate.

Recebido em: 15/06/2007

Reencaminhado em: 16/09/2007

Aprovado em: 14/02/2008

Wolney de Andrade Martins Luiz Felipe da Silva Pinto José Feres Abido Mirandal Ednéia Tayt-Sohn Martuchelli Moço

Relata-se a experiência da realização de prova prática no concurso para seleção de médicos residentes no Centro Universitário Serra dos Órgãos, Teresópolis (RJ). Houve uma primeira fase com prova teórica $(P T)$ de múltipla escolha e uma segunda fase com prova prática presencial (PP), ambas eliminatórias e classificatórias. As cinco áreas básicas do ensino médico foram avaliadas por meio do exame clínico de dois pacientes - um clínico ou cirúrgico e outro da área materno-infantil, conforme sorteio. A PP objetivou avaliar atitudes, habilidades e conhecimentos. Houve capacitação de dois tipos de bancas: a primeira com docentes das áreas clínica e cirúrgica, dita clínico-cirúrgica (CC), e a segunda com docentes das áreas de pediatria, tocoginecologia e saúde coletiva, chamada materno-infantil e preventiva (MIP). Não houve correlação significativa entre as notas da PT e as da PP. A PP foi determinante para a classificação final em cinco dos seis programas oferecidos. Houve correlação entre as notas das bancas CC e MIP $(r=0,483$, $p<0,001)$. Houve uniformidade das notas intrabanca e interbanca. A PP é exeqüível, segura e importante instrumento para a adequação do ensino de graduação em Medicina às diretrizes curriculares.

This paper relates the experience of a hands-on test model for the selection of medical residents in Serra dos Órgãos Universitary Center, Teresópolis, RJ. There was a first phase with a multiple-choice theoretical test (TT) and a second one with hands-on evaluation performed at the bedside (HO), both with eliminatory and classificatory effect. The five basic areas of medical teaching were evaluated through clinical examination of two patients: one from the clinical or surgical units and another from the maternal-child unit, selected at random. The HO test aimed to evaluate attitudes, skills and knowledge. There were two types of examination boards: the first was composed by teachers from the clinical and surgical areas, the so called clinical-surgical (CS) area and the second by teachers from the pediatric, obstetric and public health areas, called maternal-child and preventive $(M C P)$ area. There was no correlation between TT an HO. The $H O$ was responsible for final classification in five of the six residency programs offered. There was a correlation between CS and MCP scores $(r=0.483, p<0.001)$ and uniformity in the evaluation in each board as well as between the different boards. The HO evaluation model showed to be feasible and secure and is an important instrument for adapting medical teaching to the Brazilian curricular guidelines. 


\section{INTRODUÇÃO}

A residência médica (RM) é definida por lei federal como ensino de pós-graduação caracterizado por treinamento em serviço ${ }^{1}$. Compreende, assim, formação integral e ampliada em habilidades, atitudes e conhecimentos. Sua excelência é reconhecida, sobretudo, pelo modelo de formação que extrapola a transmissão passiva e estritamente cognitiva que predominou no ensino médico.

A implementação dos primeiros programas de RM no Brasil data da década de 1940 - Hospital das Clínicas da Universidade de São Paulo, SP (1944) e Hospital dos Servidores do Estado, RJ (1948)² -, e a regulamentação legal ocorreu em $1977^{3}$. Portanto, ainda é um processo novo se comparado ao ensino de graduação em Medicina no Brasil, que completa 200 anos. A Lei 6.932, de 07/07/1981, determinou, de modo genérico, a necessidade de processo de seleção para admissão aos programas de RM. Inicialmente, foi feito a critério de cada instituição. Houve experiências diversas incluindo a prova prática (PP). Esta, freqüentemente, se voltava à especialidade à qual o médico se candidatava. Refletia a especialização precoce embutida no curso de graduação. Traduzia também as práticas corporativistas, com notório privilégio aos egressos da própria instituição, e outros vícios de avaliação.

A Comissão Nacional de Residência Médica (CNRM) objetivou reduzir o caráter subjetivo da PP de então e optou por assegurar o acesso democrático. Uniformizou um modelo de prova objetiva, igualitária, com questões de múltipla escolha, distribuídas nas cinco grandes áreas do conhecimento médico. Entretanto, as limitações tornaram-se evidentes: (1) avaliação exclusivamente cognitiva; (2) incremento dos "cursos preparatórios" e, sobretudo, (3) a influência sobre os projetos pedagógicos dos cursos de graduação.

Em 2004, a CNRM acatou sugestões emanadas da Associação Brasileira de Educação Médica (Abem) e abriu a possibilidade da $\mathrm{PP}^{4}$. Em 2005, realizou a I Oficina Nacional de Avaliação da Prova Prática e à época contabilizou apenas oito instituições que a realizaram, num universo de 360 instituições credenciadas ${ }^{5}$. Nos anos subseqüentes, houve um discreto incremento na adesão ao processo. A baixa adesão tem sido atribuída às dificuldades operacionais, ao custo elevado e à subjetividade desse modo de avaliação.

A Resolução 008/2004 da CNRM ${ }^{4}$, de 05/08/2004, estabelece a necessidade de aplicação da avaliação nas cinco áreas básicas, em ambientes sucessivos. Tal obrigatoriedade é limitante dentro da diversidade das instituições credenciadas, especialmente fora dos hospitais de ensino e hospitais gerais. Houve divergência na interpretação da resolução que normatizou a PP e observou-se uma multiplicidade de modelos que, em variado grau, tentou seguir ou, até mesmo, ignorar a exigência da abrangência nas cinco áreas ${ }^{5}$.

Este trabalho descreve a experiência de modelo próprio de PP que contemplou as cinco áreas básicas, com enfoque em sua exeqüibilidade, importância e segurança como instrumento de avaliação em processo de seleção para RM. Também analisa a realização da PP como instrumento facilitador da reforma curricular no curso de graduação em Medicina.

\section{MÉTODOS}

O concurso se deu em duas etapas sucessivas que totalizaram 1.000 pontos - a prova teórica (PT), 600 pontos, e a prova prática (PP), 400 pontos. Ambas as fases foram eliminatórias e classificatórias. A primeira fase consistiu em prova objetiva com 75 questões de múltipla escolha, distribuídas entre as cinco áreas básicas, e avaliou conhecimento teórico. A segunda fase avaliou atitudes, habilidades e aplicação do conhecimento. Os candidatos aprovados e classificados dentro de quatro vezes o número de vagas foram então convocados para a PP. Foram oferecidas 12 vagas para o primeiro ano de RM, distribuídas em duas vagas para cada programa, a saber: cirurgia geral, clínica médica, medicina de família e comunidade, obstetrícia e ginecologia, ortopedia e traumatologia, e pediatria. Quarenta e sete candidatos foram convocados para a PP e 45 compareceram.

O modelo da PP consistiu em avaliação por duas bancas sucessivas, contemplando as cinco áreas básicas da medicina. A primeira banca foi denominada clínico-cirúrgica (CC), composta por dois professores: um da área de clínica médica e o segundo da área cirúrgica. A segunda banca foi denominada materno-infantil e preventiva (MIP) e foi formada por três professores, um de cada área - tocoginecologia, pediatria e medicina preventiva. Perante a banca CC, o candidato examinou um paciente adulto internado nas enfermarias clínicas ou cirúrgicas, conforme sorteio. Na presença da banca MIP, o exame se deu em paciente pediátrico ou o binômio mãe-filho no alojamento conjunto, de acordo com o sorteio. Todos os candidatos foram submetidos ao mesmo método de avaliação, independentemente do programa ao qual se candidataram.

A dinâmica da prova consistiu na recepção aos candidatos no Hospital das Clínicas de Teresópolis Costantino Ottaviano (HCTCO), identificação, instruções, sorteio das duas bancas, encaminhamento até a primeira banca, retorno à sala de espera, encaminhamento à segunda banca e despedida. Alguns candidatos foram entrevistados ao final do exame, após escolha aleatória, pelos observadores externos designados pela Comissão Estadual de RM. A duração total do processo foi, em média, de três horas para cada candidato, divididas entre 
uma hora para a recepção e o preparo e uma hora para cada uma das duas bancas. Os candidatos foram encaminhados até a banca sorteada por um fiscal treinado. Tiveram, então, 30 minutos para proceder à anamnese e ao exame físico, sob observação direta da banca. Desta forma, a banca registrou na ficha de avaliação e registro as habilidades e atitudes dos candidatos. Imediatamente após, dirigiram-se a uma sala anexa e, em tempo máximo de 20 minutos, apresentaram hipóteses diagnósticas e um plano de investigação e de conduta, sob argüição. As bancas utilizaram os últimos dez minutos para fazer as anotações na ficha de avaliação e registro e aguardar o próximo candidato. $\mathrm{O}$ exame foi feito em três manhãs sucessivas, e cada banca avaliou quatro candidatos por manhã.

Previamente ao processo seletivo, foi realizada uma oficina de capacitação com todos os professores envolvidos. Dessa oficina resultou o treinamento, assim como modificações nos critérios e métodos. Foram capacitados quatro professores de clínica médica e quatro de clínica cirúrgica que compuseram quatro bancas formadas cada qual por um clínico e um cirurgião. Estas bancas foram denominadas por ilustres figuras da história da medicina - Hipócrates, Galeno, Willian Harvey e Robert Koch. Conjuntamente, nessa oficina, foram treinados quatro professores da área da tocoginecologia, quatro de pediatria e quatro de saúde coletiva. Estes foram agrupados nas quatro bancas MIP, denominadas Oswaldo Cruz, Carlos Chagas, Albert Sabin e Louis Pasteur. Cada banca MIP foi composta por três professores - um tocoginecologista, um pediatra e um sanitarista. Todos os professores utilizaram o mesmo instrumento de avaliação e registro, assim como a mesma metodologia.

A ficha de avaliação e registro serviu concomitantemente de roteiro e de registro gráfico do processo. Essa ficha consistiu num instrumento estruturado, construído especificamente para o exame, a partir de adaptações de outra ficha congênere utilizada na instituição para a avaliação dos alunos da graduação do novo modelo pedagógico - problematização. Os quesitos e seus respectivos parâmetros foram disponibilizados na ficha de modo a permitir a conferência e registro do desempenho do aluno durante o exame - check list. O candidato não teve acesso à ficha, para preservar o sigilo dos parâmetros ali listados. Desta forma, o candidato recebeu cinco etiquetas adesivas com sua identificação, as quais ele destacou e entregou a cada um dos cinco examinadores no momento do início do exame. Nesta ficha foram registradas as notas, assim como os comentários.

O processo de avaliação foi dividido em três eixos: das atitudes, das habilidades e da aplicação do conhecimento teórico, com pesos de $25 \%$, 25\% e 50\%, respectivamente. Cada um dos eixos foi subdividido em quesitos, e estes, por sua vez, foram delimitados por parâmetros preestabelecidos. As atitudes foram mensuradas por dois quesitos: apresentação e postura (quesito I) e relação médico-paciente (II). As habilidades foram avaliadas pela semiotécnica na aferição dos sinais vitais (III) e no exame físico (IV). A aplicação do conhecimento teórico foi avaliada pelos quesitos anamnese (V), exame físico (VI), hipóteses diagnósticas (VII), investigação diagnóstica e conduta terapêutica (VIII). Neste último quesito, foi avaliada a profundidade do conhecimento teórico apresentado nas hipóteses diagnósticas, nos planos de investigação e terapêutico e complementado pela argüição correlata. Houve total de oito quesitos avaliados e atribuição máxima de dez pontos para cada. A pontuação foi escalonada de zero a dez, de dois em dois pontos, em escala categorizada. Não foram atribuídas notas fracionadas. A soma total dos quesitos perfez 80 pontos atribuídos por cada examinador. No total, os cinco examinadores atribuíram, no máximo, 400 pontos. O critério para a aprovação foi a obtenção mínima de 200 pontos. Foram reprovados os candidatos que não alcançaram este critério, independentemente de terem sido aprovados na primeira fase ou se a soma total das duas fases fosse superior a $50 \%$.

Não houve indução de qualquer parâmetro, tal como solicitação para aferição de sinais vitais ou manobra de exame físico. O candidato recebeu um kit com um esfigmomanômetro, uma lanterna, um termômetro clínico, uma fita métrica, abaixadores de língua e um martelo de reflexos. Outros instrumentos foram colocados à disposição de acordo com o quadro clínico do paciente examinado.

Os pacientes foram selecionados após indicação e concordância dos médicos assistentes e consentimento dos próprios pacientes. Houve preocupação de evitar repetições de pacientes num mesmo dia. Facultou-se às bancas a intervenção imediata sempre que constatassem qualquer ato que ferisse princípios éticos ou técnicos que pudessem trazer agravos aos pacientes.

A PP contou com a presença de dois observadores externos, docentes de instituição onde já se realizou PP, designados pela Comissão Estadual de Residência Médica. Observaram por amostragem todas as fases do processo e procederam a entrevista com amostra aleatória de candidatos, após terminado o exame.

As notas atribuídas foram computadas em planilhas Microsoft Excel (Microsoft Corp., Redmond, Washington, EUA). Utilizou-se o nível de significância estatística de 5\% para análise dos dados deste trabalho. As associações foram medidas pelos testes de correlação de Pearson, pelo coeficiente $\mathrm{W}$ de concordância de Kendall e pelo coeficiente de correlação de postos de Spearman. As médias foram comparadas pelo teste T de Student. 


\section{RESULTADOS}

Importância da prova prática em relação ao resultado final do processo seletivo

Dos 45 candidatos presentes à $\mathrm{PP}$, dois foram reprovados nesta fase e eliminados do concurso. Considerados todos os candidatos submetidos à segunda fase, não houve associação significativa entre as notas das provas teórica e prática $(\mathrm{r}=$ 0,217 e $p=0,16$ ). A prova teórica apresentou alta freqüência de empates e não discriminou diferenças significativas entre os candidatos. Entretanto, depois de somada a nota da PP, houve mobilidade nas posições, reprovações e interferência na posição final. A PP teve correlação significativa com o resultado final em todas as especialidades, exceto clínica médica. Ou seja, a PP determinou a classificação final na maioria dos programas (Gráficos 1 a 6).

\section{GRÁFICO 1}

Migração das posições dos candidatos ao programa de Cirurgia Geral (CIR) no concurso.

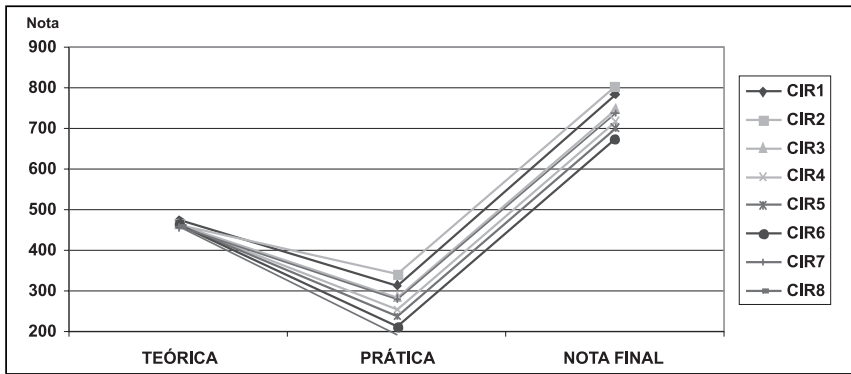

Obs.: Observar candidato CIR8, reprovado na prova prática. (Coeficiente de correlação de postos de Spearman $=1,000$ ). Nota da prova teórica de 0 a 600, e prática, de 0 a 400; nota final de 0 a 1.000 .

\section{GRÁFICO 2}

Migração das posições dos candidatos ao programa de Ortopedia e Traumatologia (ORT)

no concurso.

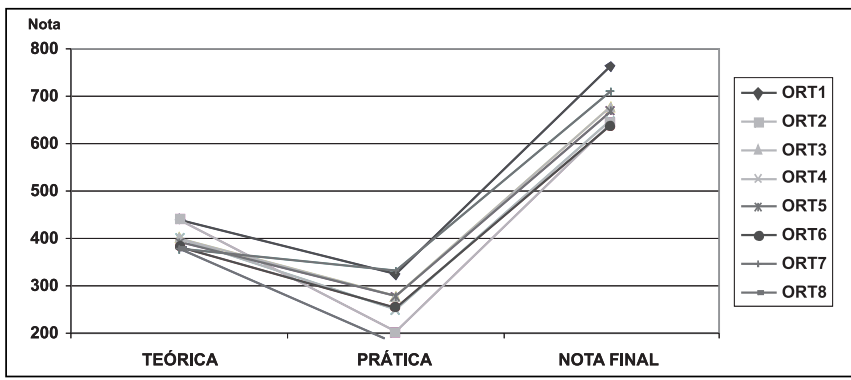

Obs.: Observar candidato ORT8, reprovado na prova prática. (Coeficiente de correlação de postos de Spearman $=0,893$ e $p<0,01$ ). Nota da prova teórica de 0 a 600 , e prática, de 0 a 400 ; nota final de 0 a 1.000

\section{GRÁFICO 3}

Migração das posições dos candidatos ao programa de Clínica Médica (CLM) no concurso.

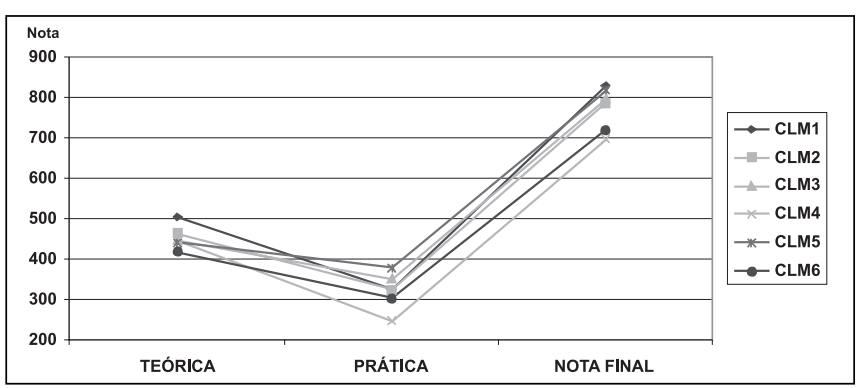

Obs.: Coeficiente de correlação de postos de Spearman $=0,657$ e p > 0,05 , não significativo. Nota da prova teórica de 0 a 600, e prática, de 0 a 400 ; nota final de 0 a 1.000 .

\section{GRÁFICO 4}

Migração das posições dos candidatos ao programa de Medicina de Família e Comunidade (MFC) no concurso.

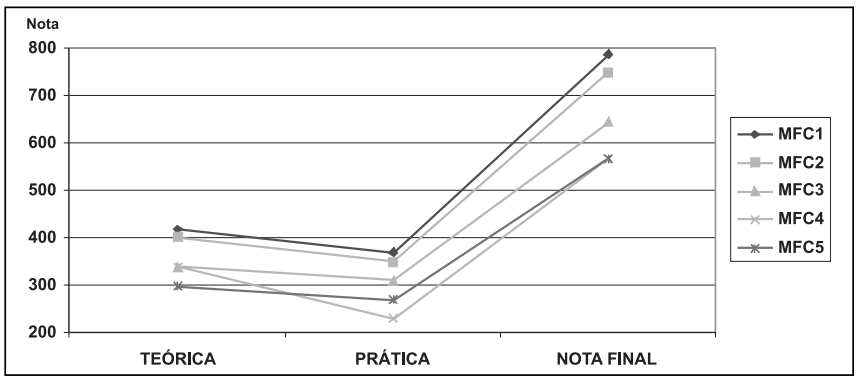

Obs.: Coeficiente de correlação de postos de Spearman $=1,000$. Nota da prova teórica de 0 a 600 , e prática, de 0 a 400; nota final de 0 a 1.000 .

\section{GRÁFICO 5}

Migração das posições dos candidatos ao programa de Obstetrícia e Ginecologia (OBT) no concurso.

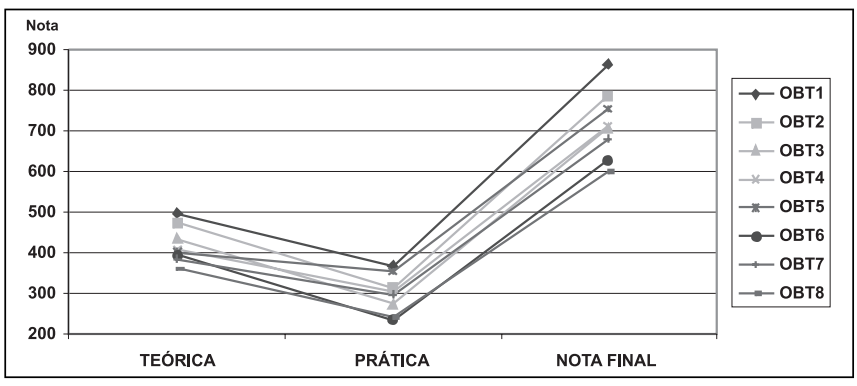

Obs.: Coeficiente de correlação de postos de Spearman $=0,929$ e p $<0,01$. Nota da prova teórica de 0 a 600 , e prática, de 0 a 400; nota final de 0 a 1.000 . 


\section{GRÁFICO 6}

Migração das posições dos candidatos ao programa de pediatria (PED) no concurso.

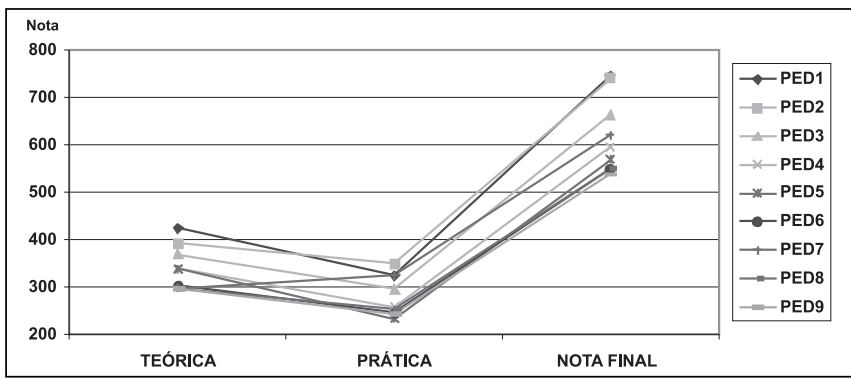

Coeficiente de correlação de postos de Spearman $=0,800$ e $p<0,01$ Nota da prova teórica de 0 a 600 e prática de 0 a 400; nota final de 0 a 1.000 .

Segurança do processo de prova prática

Relação entre notas atribuídas pelas bancas clinicocirúrgicas e materno-infantil e preventiva

Quando tomados todos os candidatos, independentemente dos programas aos quais se candidataram, houve correlação significativa entre as notas atribuídas pela banca CC e pela banca MIP $(r=0,483$ e $p<0,001)$ (Gráfico 7).

\section{GRÁFICO 7}

Correlação de Pearson entre notas da banca clínicocirúrgica (CC) e da banca materno-infantil e preventiva (MIP) de todos os candidatos submetidos à prova prática

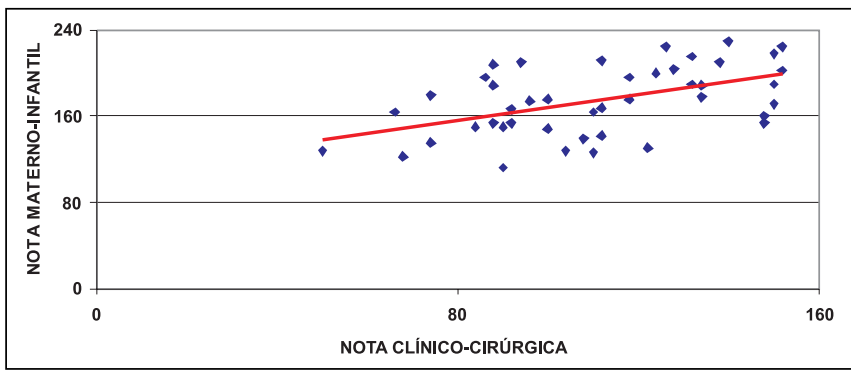

$(\mathrm{r}=0,483$ e $\mathrm{p}<0,001)$. Notas CC variam de 0 a 160, e MIP, de 0 a 240.

\section{Uniformidade intrabanca e interbanca}

\section{Bancas clínico-cirúrgicas (CC)}

Houve correlação significativa entre as notas dos examinadores 1 e 2 de cada banca CC - correlação "intrabanca" -, aferida pelo Coeficiente de Correlação de Pearson, conforme a Tabela 1.

Não houve diferença entre as notas das quatro bancas CC - correlação "interbancas" -, conforme o Teste da Mediana (Tabela 2)
TABELA 1

Coeficiente de Correlação de Pearson (r) entre as notas "intrabanca" clínico-cirúrgicas

\begin{tabular}{lcc}
\hline Bancas & r & p-valor \\
\hline Hipócrates & 0,830 & 0,002 \\
Galeno & 0,854 & $<0,001$ \\
Willian Harvey & 0,956 & $<0,001$ \\
Robert Koch & 0,911 & $<0,001$ \\
\hline
\end{tabular}

TABELA 2

Comparação das notas interbancas clínico-cirúrgicas pelo Teste da Mediana

\begin{tabular}{lcccc}
\hline \multicolumn{1}{c}{ Bancas } & Hipócrates & Galeno & Harvey & Koch \\
\hline Hipócrates & - & mediana $=$ & mediana $=$ & mediana $=$ \\
& & $112 \mathrm{p}=0,86$ & 100 & 112 \\
Galeno & - & - & $\mathrm{p}=0,09$ & $\mathrm{p}=0,41$ \\
& & & $\mathrm{P}=0,10$ & 118 \\
& & & & $\mathrm{p}=0,43$ \\
Harvey & - & & & mediana $=98$ \\
& & & & $\mathrm{p}=0,09$ \\
\hline
\end{tabular}

\section{Bancas materno-infantil e preventiva (MIP)}

Houve correlação entre os três avaliadores de cada banca MIP, exceto por um avaliador de uma das bancas - correlação intrabanca (Tabela 3). Não houve diferença entre as notas das quatro bancas MIP - correlação interbancas -, conforme o Teste da Mediana (Tabela 4).

TABELA 3

Coeficiente W de Concordância de Kendall entre os avaliadores das bancas materno-infantil e preventiva - concordância intrabanca

\begin{tabular}{|c|c|c|c|c|}
\hline \multirow{3}{*}{ Bancas } & \multirow{3}{*}{ Avaliadores } & \multirow{2}{*}{\multicolumn{3}{|c|}{$\begin{array}{c}\text { Coeficiente de Concordância de Kendall } \\
\text { Avaliadores }\end{array}$}} \\
\hline & & & & \\
\hline & & 1 & 2 & 3 \\
\hline \multirow[t]{2}{*}{ Chagas } & 1 & - & $\begin{array}{c}0,844 \\
\mathrm{p}<0,001\end{array}$ & $\begin{array}{c}0,824 \\
p<0,001\end{array}$ \\
\hline & 2 & - & - & $\begin{array}{c}0,863 \\
p<0,001\end{array}$ \\
\hline \multirow[t]{2}{*}{ Oswaldo Cruz } & 1 & - & $\begin{array}{c}0,683 \\
p=0,03\end{array}$ & $\begin{array}{c}0,767 \\
p<0,01\end{array}$ \\
\hline & 2 & - & - & $\begin{array}{c}0,962 \\
\mathrm{p}<0,001\end{array}$ \\
\hline \multirow[t]{2}{*}{ Sabin } & 1 & - & $\begin{array}{c}0,596 \\
\mathrm{p}=0,07^{*}\end{array}$ & $\begin{array}{c}0,492 \\
\mathrm{p}=0,15^{*}\end{array}$ \\
\hline & 2 & - & - & $\begin{array}{c}0,705 \\
\mathrm{p}=0,02\end{array}$ \\
\hline \multirow[t]{2}{*}{ Pasteur } & 1 & - & $\begin{array}{c}0,934 \\
p<0,001\end{array}$ & $\begin{array}{c}0,880 \\
p<0,001\end{array}$ \\
\hline & 2 & - & - & $\begin{array}{c}0,884 \\
\mathrm{p}<0,001\end{array}$ \\
\hline
\end{tabular}

* Não significativo. 
TABELA 4

Comparação das notas das interbancas materno-infantil e preventiva pelo Teste da Mediana

\begin{tabular}{|c|c|c|c|c|}
\hline Bancas & Chagas & Oswaldo Cruz & Sabin & Pasteur \\
\hline Chagas & - & mediana $=164 \mathrm{p}=0,33$ & $\begin{array}{c}\text { mediana }=168 \\
P=0,20\end{array}$ & $\begin{array}{c}\text { mediana }=168 \\
P=0,20\end{array}$ \\
\hline Oswaldo Cruz & - & - & $\begin{array}{c}\text { mediana }=178 \\
P=0,33\end{array}$ & $\begin{array}{c}\text { mediana }=176 \\
P=0,82\end{array}$ \\
\hline Sabin & - & - & - & $\begin{array}{c}\text { mediana }=184 \\
\mathrm{P}=0,50\end{array}$ \\
\hline
\end{tabular}

\section{DISCUSSÃO}

Os concursos para RM têm-se caracterizado pela elevada relação candidato-vaga, com grande número de candidatos empatados, onde uma única questão de múltipla escolha acertada pode definir a admissão à vaga. Este problema toma magnitude quando se assume que os conteúdos cobrados nas provas teóricas de múltipla escolha não refletem integralmente aqueles norteados pelas diretrizes curriculares para os cursos de Medicina no Brasil. Soma-se, ainda, o grau de subjetividade ou sorte, intrínsecos em provas de múltipla escolha.

No presente trabalho, ficou nítida a ausência de relação significativa entre as notas aferidas nas provas teórica e prática. Tanto não houve correlação entre as notas, como se observou que o determinante na colocação final foi a PP. Candidatos inicialmente empatados são claramente diferenciados após a PP. Nesta experiência, foi marcante a insuficiência de atitudes e habilidades em alguns candidatos que, embora selecionados entre os primeiros lugares na PT, foram reprovados na PP. Tais candidatos teriam grande potencial de ingresso no programa caso a PP não tivesse sido realizada.

Pinto et al. ${ }^{6}$, a partir da experiência com a PP na Faculdade de Medicina de Petrópolis, refletem que a PP serve como sinalizador para as deficiências do ensino de graduação e promovem indicadores para sua melhoria. Parece simplista limitar a PP tão-somente para aferir atitudes e habilidades, pois seguramente se presta também para medir a capacidade do candidato em correlacionar o conhecimento cognitivo apreendido na graduação com sua aplicabilidade. Serve, portanto, para verificar a capacidade de integração e aplicação do conteúdo livresco, fragmentado, em planos de cuidados ao paciente e à coletividade. Goldwasser ${ }^{7}$ estudou as expectativas quanto às competências a serem avaliadas na PP. Demonstrou que os estudantes consideraram o conhecimento a principal competência a ser aferida, ao passo que os preceptores deram primazia à avaliação das atitudes e da ética.

A PT, nos moldes atuais, foi padronizada pela CNRM com o nobre propósito de garantir admissão justa e igualitária nos diversos programas de RM no País. Entretanto, levou às distorções conhecidas: interferência nos programas político-pedagógicos das instituições de ensino superior (IES) com a valorização do conhecimento meramente cognitivo e descontextualizado da realidade do Sistema Único de Saúde (SUS). Por outro lado, Afonso et al. ${ }^{8}$ pontuaram, a partir da experiência acumulada na Universidade do Estado do Rio de Janeiro, que a PP valoriza competências e habilidades, e funciona como indicador da implantação das diretrizes curriculares no curso de graduação em Medicina. Ao se objetivar a formação de profissional voltado às necessidades do SUS e à integralidade da assistência, é coerente cobrar tais competências em todo e qualquer concurso para médico. A PP serve, portanto, ao mesmo tempo, como instrumento de aferição do grau do comprometimento institucional com as diretrizes curriculares e com os processos de transformação curricular.

A influência dos concursos de RM sobre a graduação é anterior ao internato. Fava et al. ${ }^{9}$ relataram que $76 \%$ dos alunos do sétimo ao nono períodos do curso de graduação em Medicina da Universidade Federal de Juiz de Fora manifestaram interesse em se matricular num curso preparatório para concurso de RM. E aqueles que responderam negativamente o fizeram por falta de recursos financeiros. Segundo Ferreira et $a l .{ }^{10}$, há opção clara dos internos de Medicina pela busca do conhecimento teórico oferecido nos cursos preparatórios, em detrimento das vivências proporcionadas pelo internato. A justificativa apresentada pelos discentes é a elevada concorrência pelas vagas de RM. Esta mobilização pelas provas de RM tem levado ao esvaziamento das enfermarias e ambulatórios. Uma vez provado que a PP define a colocação nos concursos para RM, é lógico inferir que se poderia iniciar um movimento reverso com a volta à valorização das atividades práticas do curso de graduação em Medicina.

Em nossa instituição, optou-se pela nomeação de professores do próprio hospital de ensino para a composição da banca. Tal fato foi deliberado e objetivou a valorização do docente ligado às atividades práticas. A identificação por parte do aluno da graduação de que o professor da enfermaria ou 
ambulatório poderá ser seu futuro argüidor numa banca de PP aproxima as vivências do internato ao concurso para RM.

Goldwasser ${ }^{7}$ revisou os modelos de PP aplicados em nosso meio à época do XLIII Congresso da Abem, em 2005. Citou a multimídia, os exames objetivos estruturados (Osce), a PP presencial e a entrevista dirigida. A prova com utilização de recursos de multimídia oferece como vantagens a padronização e a independência do examinado e examinador. É de fácil reprodução e utilização em instituições não universitárias. Entretanto, é considerada uma prova teórica mais bem elaborada, pois não reproduz a interação médico-paciente, tampouco consegue aferir atitudes e habilidades. As Osce despontam pela facilidade de padronização de situações, mas, em geral, têm alto custo e limitam as possibilidades de interação. São muito utilizadas nos programas de RM nos Estados Unidos da América. Somente apresentam custo-benefício favorável quando aplicadas a grande número de candidatos ${ }^{11}$. As entrevistas dirigidas ficaram estigmatizadas pela subjetividade e por não aferirem habilidades. Modelos outros que não a prova prática presencial, em análise inicial, parecem ganhar pela padronização e uniformidade da avaliação. Mas perdem, em muito, pela riqueza de possibilidades de exploração que só o contato direto do candidato com o paciente pode proporcionar. Isto toma vulto quando se busca a adaptação do ensino às realidades do SUS. Assim, o alto custo e esforço que tais processos demandam podem onerar os candidatos.

Os maiores temores quanto à realização da PP por parte das Comissões de Residência Médica (Coreme) são a subjetividade e a falta de padronização, em especial quando se trabalha com múltiplas bancas e grande número de candidatos. Por outro lado, os candidatos temem o favorecimento de egressos da própria instituição, quando se trata de IES. No presente trabalho, demonstrou-se a segurança do processo em concurso onde $70 \%$ dos candidatos foram egressos de outras IES. Houve correlação entre as notas atribuídas nas bancas CC e MIP, e alto grau de correlação intrabanca e interbanca. Provavelmente, isto emerge do processo de padronização de quesitos e parâmetros, oficina de treinamento das bancas, montagem de bancas heterogêneas, interdisciplinares, e a avaliação por observadores externos. Os docentes participantes precisam estar motivados e cientes da importância do processo. A remuneração das bancas, assim como a ciência de que todo o processo também está sob avaliação dão caráter profissional. A utilização de checklists com padrões de atitudes e habilidades esperadas ajudou nesta experiência, como relatado na literatura, na padronização e operacionalização ${ }^{11}$.

Numa primeira análise, pode parecer haver contradição entre a PP realizada com pacientes incentivada pela CNRM/
MEC e o respeito às questões éticas. Entretanto, a ética encontra-se no respeito aos princípios fundamentais de não-maleficência e beneficência, e não no método de avaliação per si ${ }^{12}$. Esta preocupação deve estar presente em todo o processo de formação, iniciado na graduação, mas não pressupõe o afastamento do aluno ou candidato do paciente.

Tal assunto foi objeto de análise do Conselho Regional de Medicina do Estado de São Paulo (Cremesp) ${ }^{13}$, quando avaliou a validade ética da realização de concursos práticos em seleção de docentes para o ensino superior, especialmente nas áreas cirúrgicas. O Cremesp recomendou que se resguardassem os mesmos princípios éticos que pautam a prática clínica, destacando-se o consentimento esclarecido. Algumas medidas foram tomadas nesta experiência e devem, na visão de nossa Coreme, ser observadas em concursos com participação de pacientes. A Coreme deve ponderar se possui condições operacionais de garantir esses requisitos, especialmente nos concursos com número expressivo de candidatos.

Destacam-se medidas que foram tomadas e consideradas relevantes: (1) todos os candidatos devem ser previamente identificados como médicos ou alunos do último período do curso, com documentação comprobatória depositada na coordenação do concurso; (2) todos devem ser identificados com crachá; (3) restringir a circulação dos candidatos dentro do hospital e fazê-la acompanhada por funcionário; (4) portar, obrigatoriamente, uniforme completo; (5) esclarecimento prévio ao candidato de todo o processo de avaliação, suas atribuições e limitações; (6) obter consentimento pós-informado do paciente e de seu respectivo médico assistente, assim como do chefe de clínica; na medida do possível, envolver os chefes de clínica e assistentes na avaliação; (7) durante o processo, manter o candidato sob observação direta e permanente da banca; (8) proibir a realização de atos e procedimentos, limitando o contato à anamnese e ao exame físico; (9) excluir do exame físico os procedimentos que demandem ambiente reservado e exposição, tais como toques retal e vaginal; (10) disponibilizar ambiente reservado do paciente para a argüição; (11) facultar à banca a intervenção e suspensão da avaliação sempre que constatado qualquer ato que contrarie os princípios éticos.

A heterogeneidade dos modelos de PP experimentados até então parece vir das dificuldades operacionais de se atender à Resolução 008/2004 da CNRM4 . Cada instituição tenta adaptar essa resolução à sua realidade institucional. O Ministério da Educação, ciente de tais dificuldades, criou uma comissão de assessoramento com o objetivo de orientar a realização da $\mathrm{PP}^{14}$. O modelo ora proposto consistiu em substituir a avaliação seqüencial nas cinco áreas básicas - o que a torna longa e custosa - pela visão de docentes dessas mesmas áreas. Não há 
doentes da clínica cirúrgica ou da clínica médica, mas, sim, pacientes com histórias, fatores de risco, agravos, ou seja, um largo espectro de possibilidades a serem exploradas numa PP. A pressão arterial pode e deve ser aferida corretamente seja num paciente "clínico" ou "cirúrgico". Nesta linha de raciocínio, agruparam-se cenários afins: um da clínica de adultos e outro materno-infantil. Optou-se por agregar a avaliação do docente da área da saúde coletiva ao materno-infantil, pelo consenso de que este cenário seria o mais rico em possibilidades. Entretanto, todos utilizaram o mesmo instrumento de avaliação. Foi consenso nas oficinas preparatórias que o agrupamento dos docentes em duas bancas seria uma atitude coerente com a proposta da integralidade na assistência.

A opção da utilização do ambiente nosocomial objetivou maior controle do processo quanto a uniformização e facilidades operacionais no contexto de uma primeira experiência. Há, entretanto, uma expectativa de utilizar cenários ambulatoriais numa próxima experiência.

\section{CONCLUSÕES}

Nesta experiência, a divergência entre os resultados da PT e PP foi educativa na necessidade da aplicação da segunda. A uniformidade de notas intrabancas e interbancas evidenciou que, desde que haja planejamento, treinamento e preocupação ética, o processo da PP é seguro e justo. A PP reúne a possibilidade de avaliação mais completa - integração entre conhecimento, atitudes, habilidades e ética - e é coerente com as propostas das diretrizes curriculares para o curso de graduação em Medicina.

\section{AGRADECIMENTOS}

Aos professores do Unifeso, que generosamente aceitaram o desafio da realização da prova prática na instituição: Alcemir Gonçalves Pettersen, Antonio José dos Santos, Cláudio Luiz Bastos Bragança, Daniel Ricardo Soranz, Jones Walter Ribeiro, Júlio Maria de Oliveira, Lorilea Chaves de Almeida, Luciana Maria Borges da Matta Souza, Luciana Nogueira de Barros, Marcos Filgueiras, Marcus Vinicius Raposo Câmara, Maria Célia Marques da Fonseca, Maria de Fátima da Silva Moreira Jorge, Mário Antônio Soares Simões, Rosane Rodrigues Costa, Sérgio Pettendorfer, Túlio Augusto de Azevedo, Valéria Francisca do Nascimento, Vera Lúcia Gonçalves Pacheco e Washington Sérgio Gonçalves Milezi.

Aos observadores externos Ana Lúcia Teixeira Pinto e Floriano Achão, docentes da Faculdade de Medicina de Petrópolis, pelas sugestões.

À Direção do HCTCO, pelo apoio logístico, em especial, à doutora Catherine Moura da Fonseca Pinto.

\section{REFERÊNCIAS}

1. Brasil. Lei Federal 6.932 de 07/07/1981 publicada no Diário Oficial da União em 09/07/1981. Disponível em: http:// www.mec.gov.br/sesu. [Acesso em 23 de janeiro de 2007].

2. Nunes MPT. Residência médica no Brasil - situação atual e perspectivas. Boletim da ABEM. 2003; 31:2-3.

3. Brasil. Decreto Federal 80.281 de 05 de setembro de 1977, publicado no Diário Oficial da União em 06/09/1977. Disponível em: http:/ / www.mec.gov.br/sesu. [Acesso em 23 de janeiro de 2007].

4. Brasil. Ministério da Educação. Comissão Nacional de Residência Médica. Resolução 008/2004 da CNRM. Dispõe sobre o processo de seleção pública dos candidatos aos Programas de Residência Médica [2004]. Disponível em: http:/ / www.portalmec.gov.br/sesu. [Acesso em 23 de janeiro de 2007].

5. Nunes MPT. Oficina nacional de avaliação dos procedimentos da prova prática aplicada durante o processo seletivo de residência médica. Disponível em: http:/ / portal. mec.gov.br/sesu/arquivos/pdf/cnrm/avalprovapratica. pdf. [Acesso em 23 de janeiro de 2007].

6. Pinto ALT, Gorini CC, Zamboni MJG, Plácido, MV, Koury ICV. Experiência da Faculdade de Medicina de Petrópolis: o desafio da avaliação prática no concurso de residência médica. Anais do $44^{\circ}$ Congresso Brasileiro de Educação Médica; 24-27 set. 2006; Gramado, ABEM, 2006. p. 481.

7. Goldwasser RS. A prova prática no processo de seleção do concurso de residência médica. Rev. Bras. Educ. Med. 2006; 30:115-124.

8. Afonso DH, Fernandes JCSA, Silveira LMC, Deveza M, Amaral NR, Miranda Filha N, Marques EP. Residência médica: competências e habilidades valorizadas na etapa do processo seletivo como indicador de implementação das diretrizes curriculares. Anais do $44^{\circ}$ Congresso Brasileiro de Educação Médica; 24-27 set. 2006; Gramado, ABEM, 2006. p. 474.

9. Fava AS, Oliveira RSO, Cunha PHM, Choi CMK, Chehuen Neto JA, Sirimarco MT. Cursinhos preparatórios para prova de residência médica: expectativas e opiniões. Anais do $44^{0}$ Congresso Brasileiro de Educação Médica; 24-27 set. 2006; Gramado, ABEM, 2006. p. 485.

10. Ferreira RC, Marchi AMG, Nunes PAL, Ribeiro LO, Pereira, AG, Silva RF, Varga, CRR, Campos RG, Marchi CMG, Gomes PS. Curso preparatório para residência médica: a percepção dos estudantes de medicina. Anais do $44^{\circ}$ Congresso Brasileiro de Educação Médica; $24-27$ set. 2006; Gramado, ABEM, 2006. p. 476-7. 
11. Accreditation Council for Graduate Medical Evaluation (ACGME) and American Board of Medical Specialists (ABMS). Toolbox os assessment methods. Version 1.0. Summer 2000. 20p. Disponível em: www.acgme.org/ acWebsite/RRC_380/380_toolboxVersion.pdf. [Acesso em 21 de abril de 2007].

12. Centro de Bioética do CREMESP. Alerta ético. Jornal do CREMESP, ed. 240, n. 8, p. 14, 2007. Disponível em http:/ / www.cremesp.org.br. [Acesso em 01 de setembro de 2007].

13. Conselho Regional de Medicina do Estado de São Paulo. Parecer 84.971/01. Disponível em http://www.cremesp. org.br. [Acesso em 01 de setembro de 2007].

14. Brasil. Ministério da Educação. Portaria MEC/SESU número 645 de 15 de setembro de 2006. Publicada no DOU sob o n.179, seção 2, p.15, em 18/09/2006. Disponível em: http://www.mec.gov.br/sesu. [Acesso em 18 de fevereiro de 2007].
CONFLITOS DE INTERESSE

Declarou não haver.

\section{ENDEREÇO PARA CORRESPONDÊNCIA}

Centro Universitário Serra dos Órgãos

Coordenação da Residência Médica

Wolney de Andrade Martins

Av. Alberto Torres, 111

Alto - Teresópolis

CEP 25964-000 / RJ

E-mail: residenciamedica@feso.br 